\title{
The Association of Family Functions Among Juvenile Delinquent Children in Rehabilitation Centres in Nairobi and Kiambu Counties-Kenya
}

\author{
Ruth Kioko* \\ College of Health Sciences, University of Nairobi, P.O Box 30197-00100, Nairobi, Kenya \\ Doctor Teresia Mutavi \\ College of Health Sciences, University of Nairobi, P.O Box 30197-00100, Nairobi, Kenya
}

\begin{abstract}
The research was not funded by any organization or institution.
\end{abstract}
\section{Abstract}

Background: Juvenile delinquency is a serious problem in Kenya. There is a great concern with the growing numbers of children who are in the rehabilitation centres in Kenya. Previous studies in this field has mostly dwelt on the rehabilitation process of the juvenile delinquent children, and not much on the cause. This study sought to find out if family functions may contribute or lead to juvenile delinquency among children in Nairobi and Kiambu Counties.Objective: To identify the prevalent family functions among juvenile delinquent children in rehabilitation centres in Nairobi and Kiambu counties. Methodology: A cross-sectional descriptive design was used, involving purposive sampling technique. Face to face interview was used to collect data from a total number of 113 participants, 60 from Getathuru rehabilitation centre and 53 from Kirigiti rehabilitation centre. A socio demographic data questionnaire, Family Assessment Device and Brief Family Relationship Scale was used. The study was done for a period of 12 weeks. Results: The study established that among the respondents, the majority $(95.6 \%)$ were from families which were unstable compared to mere $4.4 \%$ who were from families that were functional.Conclusion: The family is a system in which each member has a significant influence on all other members. Hence, family functions may determine if a child will be delinquent or not. A family that is dysfunctional is more likely to lead to juvenile delinquency than a family that is functional. New strategies in the rehabilitation process focusing on the family and its functions is important instead of dealing with the child as the only source of the problem. Involvement of professional counsellors and therapist to facilitate the rehabilitation of the children instead of using criminal justice personnel is highly recommended in order to deal with the root cause of juvenile delinquency.

Keywords: Juvenile delinquency, family functions

DOI: $10.7176 /$ RHSS/10-21-06

Publication date: November $30^{\text {th }} 2020$

\section{0 Background information}

Youth delinquency and crime is a major problem in Nairobi (UN-Habitat, 2016). This trend has been associated with the increase of juvenile delinquency. There is a growing concern with the growth and prevalence of Juvenile delinquents (JD) in rehabilitation centres in Kenya (Nguku etal, 2017).

The family is usually the first environment within which an individual interacts (Maree, 2008). Family functionality is a multi-dimensional constraint that demonstrates activity and interaction in a family in carrying out critical tasks, in keeping family development and well-being as well as maintaining its integrity (Hadfield etal., 2018). The behaviour of family members has an impact on the functionality of a family. Family functionality is a process and can result in normal or abnormal behaviour, (Bt W.N.Zulkifli etal., 2017).

Further, change of caretakers before age of ten, physical punishment, poor supervision, and poor communication within the family were also identified as risk factors for juvenile delinquency (Boakye, Farrington\& Loeber, 2008).

Family conflicts is associated with juvenile delinquency, and that interfamily conflict is a common feature in the American families today. Modern researchers supported the view that children who were brought to homes where they witnessed violence and discord later exhibited emotional and behaviour disturbances (Siegel \& Welsh, 2014).

Family factors like stability, cohesiveness, and adaptability play a crucial role in influencing juvenile delinquency. Family functions are also influenced by social, economic, spiritual and cultural conditions which vary all over the world (Sanni etal, 2010).

A study done in Bahrain (Middle East) found out that, family warmth, quality of communications, discipline and other aspects of care related to a parent-child relationship was superior in non-delinquent families than in delinquent families (Alnasir \& Al-falaij, 2016). They attributed these occurrences to rapid modernization which has highly influenced family structure disintegration and also family functions. 
Lack of parental supervision, family disruption and lack of information on the importance of family cohesion on raising up children has led to many children being delinquent (Gudadi, 2013). A study done in Nairobi slums by Kabiru etal (2014), revealed that parental monitoring whether in high or low levels of adversity lowers the level of delinquency in children. Parental closeness facilitates support to the children enhancing open communication, self-expression and helping children adapt easily as they negotiate different stages in their lives and other life stressors (Kabiru etal, 2014).

Family functions are diverse and important in the lives of all children. Any form of family dysfunction may destabilize the lives of children emotionally, physically, socially and psychologically (Rwengo, 2017).

\subsection{Methodology}

A cross-sectional descriptive study design was used, incorporating quantitative study. The study was conducted in Getahuru (Nairobi) and Kirigiti (Kaimbu) rehabilitation centres which are also the reception and assessment centres in Kenya for boys and girls respectively. Children who are in conflict with the law are transferred to the 2 centres after completing the judicial process (UNICEF report, 2012). They temporarily stay here for about 12 weeks before being transferred to other rehabilitation centres across the country where they serve their commitment period. The assessment of their risk level is done in the 2 centres and ranges from low, medium to high and determines their placement (Vincent, Guy \& Grisso, 2012). For the high-risk cases for girls, they are retained in Kirigiti center since there are only 2 rehabilitation schools for girls in Kenya; while, the low and medium risks are committed to Dagorreti centre. For the boys, they are placed in the other 8 rehabilitation centres throughout the country to serve their term. The placement transfer is done every 3 months.

\subsection{Ethical consideration}

This study was approved by the ethical and research committee (ERC), Kenyatta National hospital and University of Nairobi (UON) with Approval number P877/12/2108. Once the project was approved the researcher forwarded it to the National Commission for Science, Technology, and Innovation (NACOSTI) for permit application since the study was dealing with minors. From NACOSTI the researcher obtained a permit to carry out the research in Kirigiti and Getathuru rehabilitation centres. The research permit was presented to the principal secretary in the ministry of labour and social protection since the participants were children in conflict with the law. Permission was granted and the county commissioners of Nairobi and Kiambu counties were served with copies of the permit to allow access to the 2 facilities.

Fisher et al., (2012) formula was used for sample size, at a permissible error of $5 \%$ and prevalence of $50 \%$. Since the targeted population was less than 10,000 (160), Yamanes formula (1967) was used to determine the sample size. The study comprised of $\mathrm{N}=113$ respondents; 53 participants from Kirigiti girls' rehabilitation centre and 60 from Getathuru boys' rehabilitation centre. Their ages were between 10-17 years and were from all types of families.

\subsection{Recruitment procedure and data collection}

Purposive sampling technique was used for this study (Saunders, Lewis \& Thornhill, 2016). The researcher used the files that contained detailed information about all the children arriving at the rehabilitation centres, with the help of the probation officers. If the information indicated that a child was from any type of family and met other inclusion criteria, he/she was recruited for the study. Before meeting with those recruited, the researcher reported back to the manager's office and took him/her through the consent since he/she was the guardian of the children in the rehabilitation centre. After the consent was signed, the researcher requested the probation officer to identify those recruited. The researcher established rapport with those who were recruited at individual level and then he/she was taken through the assent form individually in a private room. Simple and clear language was used to enhance understanding. If in agreement to participate in the study, the participants signed the assent form in the presence of a witness (researcher) and finally the researcher signed. Once the consent and assent were obtained, the participant was taken through the questionnaires step by step until all the information was recorded. The interview took about 30 minutes. The researcher debriefed and thanked participant for his/her time and helpful information.

Further, explanation of the reasons for the study was done and the age of each individual child was considered to enhance understanding. No coercion was used, and the participants who opted out were allowed to do so freely. Confidentiality of the information gathered was maintained, unless in circumstances of any danger to self or other persons. The documents were securely stored, and the final report was anonymous and not bearing any names of the participants. The data was collected over a period of 12 weeks. Quantitative Data was analyzed using statistical package for social sciences SPSS v25. Descriptive statistics used frequency and proportions to define variable. Findings was presented in the form of tables and narrative. 


\subsection{Instruments}

A locally designed questionnaire was used to collect socio-demographic data for the 10-17 years old respondents. The Family Assessment Device-General functioning scale (FAD) and Brief family relationship scale (BFRS) was used to assess functioning from the respondents' families. FAD was authored by Epstein, Baldwin, and Bishop in 1983. It is a widely used and validated instrument and has the advantage over other tools that measure family functioning in that, it focuses on family functioning from a multidimensional stance. It has 12 items about family communication and support. It is recommended for all ages (Epstein, Baldwin \& Bishop, 1983). In the United Kingdom and Ontario, FAD was used to survey the level of family functioning in families with children suffering from mental disorders (mood or anxiety disorders, ADHD) (Wilson etal, 2010).

There is the reliability value of the FAD instrument for measuring family functionality, and it was .971 exceeding the alpha value of 0.6. The reliability of less than 0.60 is considered low and unacceptable, an Alpha value between 0.60 and 0.80 is acceptable, while the Alfa exceeding 0.80 is considered good, (Bt W.N.Zulkifli etal., 2017).

The Brief Family Relationship Scale (BFRS) assessed cohesion, expressiveness, and conflict within the participants' families. It has been used widely in western cultures, American Indians, East, and South Asian cultures among others, and it has 12 items (Fok,Allen \& Henry, 2014). BFRS was used in 284 Alaska Native youths (12to 17 years) to assess the level of their family functioning. From the results, BFRS was found suitable for use in other non-western cultures and mostly collectivist cultural groups (Ching Fok, Allen \& Henry, 2011).

These instruments had not been used in Kenya before. Most of the studies done in this field had used researcher tailored tools.

\subsection{Results and discussion}

Socio-Demographic Characteristics

Table 1: Socio-Demographic Characteristics

\begin{tabular}{|c|c|c|c|c|c|}
\hline & \multicolumn{2}{|c|}{ Institution } & \multirow[b]{2}{*}{ Total } & \multirow[b]{2}{*}{$\%$} \\
\hline & & Kirigiti & Getathuru & & \\
\hline \multirow[t]{3}{*}{ age brackets } & Between $10-12$ years & 3 & 9 & 12 & 10.6 \\
\hline & Between $13-15$ years & 33 & 39 & 72 & 63.7 \\
\hline & Between 16-17 years & 17 & 12 & 29 & 25.7 \\
\hline \multirow[t]{2}{*}{ Gender } & Male & 0 & 60 & 60 & 53.1 \\
\hline & Female & 53 & 0 & 53 & 46.9 \\
\hline \multirow{3}{*}{$\begin{array}{l}\text { Education } \\
\text { placement }\end{array}$} & Lower primary & 1 & 8 & 9 & 8.0 \\
\hline & Upper primary & 49 & 51 & 100 & 88.5 \\
\hline & Secondary & 3 & 1 & 4 & 3.5 \\
\hline \multirow[t]{5}{*}{$\begin{array}{l}\text { Person living with at } \\
\text { time of arrest }\end{array}$} & $\begin{array}{l}\text { Both mother and father } \\
\text { (biological) }\end{array}$ & & & 22 & 19.5 \\
\hline & Mother only & & & 38 & 33.6 \\
\hline & \begin{tabular}{|l|} 
Father only \\
\end{tabular} & & & 5 & 4.4 \\
\hline & Live with a grandparent & & & 16 & 14.2 \\
\hline & $\begin{array}{l}\text { Live with uncle/aunt/older } \\
\text { sibling } \\
\text { Biological mother and } \\
\text { stepfather }\end{array}$ & & & 13 & 11.5 \\
\hline
\end{tabular}

Children between age brackets of 13-15 years formed the majority (63.7\%) and those between 16-17 years were $25.7 \%$. On the respondents' gender, the study established that males were majority (53.1\%) and females constituted $46.9 \%$, and their education placement at the time of arrest indicated that the majority were in the upper primary $(88.5 \%)$ and a mere $3.5 \%$ were in secondary school. At the time of arrest $33.6 \%$ of the respondents were living their mothers only, $19.5 \%$ with their biological parents, $16.5 \%$ with a biological mother and step father, while $25.7 \%$ lived with either their grandparent, uncle, aunt or older sibling (Table 1).

Table 2: Family Assessment Device - General Functioning Scale

\begin{tabular}{|l|l|c|c|}
\hline \multicolumn{2}{|c|}{} & $\mathrm{N}=113$ & Percent \\
\hline Functionality & Functional & 5 & $(4.4)$ \\
\cline { 2 - 4 } & Dysfunctional & 108 & $(95.6)$ \\
\hline
\end{tabular}

Using the family assessment device-general functioning scale, the study established that among the respondents in the study, the majority $(95.6 \%)$ were dysfunctional compared to mere $4.4 \%$ who had functional families (Table 2). 


\section{Brief Family Relationship Scale}

Table 3a: Cohesion in the family

\begin{tabular}{|l|r|r|r|r|r|r|}
\hline & Not at all & \multicolumn{2}{|l|}{ Yes-a lot } & \multicolumn{2}{|c|}{ Somewhat } \\
\hline In our family, we really help and support each other & Fr & \multicolumn{1}{c}{$\%$} & \multicolumn{1}{|c|}{ Fr } & \multicolumn{1}{c}{$\%$} & Fr & \multicolumn{1}{c}{$\%$} \\
\hline In our family, we spend a lot of time doing things together at home & 82 & 72.6 & 1 & .9 & 30 & 26.5 \\
\hline In our family, we work hard at what we do in our home & 109 & 96.5 & & & 4 & 3.5 \\
\hline In our family, there is a feeling of togetherness & 72 & 63.7 & 9 & 8.0 & 32 & 28.3 \\
\hline My family members really support each other & 83 & 73.5 & 1 & .9 & 29 & 25.7 \\
\hline I am proud to be a part of our family & 81 & 71.7 & 1 & .9 & 31 & 27.4 \\
\hline In our family, we really get along well with each other & 64 & 56.6 & 12 & 10.6 & 37 & 32.7 \\
\hline
\end{tabular}

From the responses, the study noted that most of the respondent's family $(72.6 \%)$ lacked cohesion as they rarely helped and supported each other; while $96.5 \%$ did not spend time doing things together, $63.7 \%$ did not work hard at what they did at home, $73.5 \%$ rarely had feeling of togetherness and $71.7 \%$ family members did not at all really support each other. Assessing if they were proud to be a part of their family, most (56.6\%) indicated not at all and $71.7 \%$ rarely got along well with each other in their families (Table 3a). Therefore, the majority of the participants experienced disunity, little or no support and did not spend time together with other family members and neither were they proud to be associated with their families.

Table 3b: Expressiveness in the family

\begin{tabular}{|l|r|r|r|r|r|r|}
\hline & Not at all & \multicolumn{3}{|c|}{ Yes-a lot } & \multicolumn{2}{|c|}{ Somewhat } \\
\hline In our family, we can talk openly in our home & Fr & \multicolumn{1}{c|}{$\%$} & Fr & \multicolumn{1}{c}{$\%$} & Fr & $\%$ \\
\hline In our family, we sometimes tell each other about our personal problems & 90 & 79.6 & 1 & .9 & 22 & 19.5 \\
\hline In our family, we begin discussions easily & 94 & 83.2 & 1 & .9 & 18 & 15.9 \\
\hline
\end{tabular}

On the expressiveness in the family, the majority (79.6\%) cited that they did not at all talk openly in their home, $83.2 \%$ did not express their personal problems and $75.2 \%$ did not start discussions easily (Table $3 b$ ). This results demonstrated most of the participants had no freedom of expression within their families which further worsened the disunity and dysfunctionality.

Table 3c: Conflicts in the family

\begin{tabular}{|c|c|c|c|c|c|c|}
\hline & \multicolumn{2}{|c|}{ Not at all } & \multicolumn{2}{|c|}{ Yes-a lot } & \multicolumn{2}{|c|}{ Somewhat } \\
\hline & $\mathrm{Fr}$ & $\%$ & $\mathrm{Fr}$ & $\%$ & $\mathrm{Fr}$ & $\%$ \\
\hline In our family, we argue a lot & 19 & 16.8 & 72 & 63.7 & 22 & 19.5 \\
\hline In our family, we are really mad at each other a lot & 32 & 28.3 & 41 & 36.3 & 40 & 35.4 \\
\hline In our family, we lose our tempers a lot & 22 & 19.5 & 72 & 63.7 & 19 & 16.8 \\
\hline In our family, we often put down each other. & 25 & 22.1 & 58 & 51.3 & 30 & 26.5 \\
\hline My family members sometimes are violent & 7 & 6.2 & 60 & 53.1 & 46 & 40.7 \\
\hline In our family, we really help and support each other & 75 & 66.4 & 9 & 8.0 & 29 & 25.7 \\
\hline
\end{tabular}

Assessing the presence of conflicts in their families, the study established that $63.7 \%$ argued a lot, $36.3 \%$ were mad with other family members a lot; and $63.7 \%$ lost tempers a lot, and $51.3 \%$ often put down each other a lot. Probing if the family members sometimes were violent, a majority (53.1\%) indicated a lot of violence and $40.7 \%$ somewhat violent. Further, $66.4 \%$ indicated that they did not at all help or support each other in their families (Table 3c). Conflicts was noted to be common with the majority of the respondents experiencing high levels of negative emotions within their families.

\subsection{Discussion}

On general functioning, the study established that the majority $(95.6 \%)$ of the respondents' families were dysfunctional. These findings were consistent with (Rwengo, 2017), in her study in Eldoret rehabilitation centre, which established that family instability/dysfunctionality was a major cause of juvenile delinquency since it may destabilize the lives of children emotionally, physically, socially and psychologically. Mwanjala, (2015) had similar findings in a study done in Taita-Taveta County (Kenya) which established that quality of parenting was highly rated as a cause of juvenile delinquency. This was because of poor and/or lack of parental supervision, rejection by a mother and lack of parental involvement with their children. Parental supervision and involvement may enhance communication and support in a family bringing about collaboration between parents and their children, promoting the level of family functioning especially in the domains of cohesion, communication and conflict resolution.

This study found out that a majority of the respondent's families lacked cohesion and expressiveness, and experienced high level of conflicts accompanied by intense negative emotions. This concurs with a study done in Ghana (Boakye, Farrington \& Loeber, 2008) which found out that, physical punishment, poor supervision, and 
poor communication within the family were risk factors for juvenile delinquency. Family conflict was a cause of juvenile delinquency, and that interfamily conflict was a common feature in the American/African families (Siegel $\&$ Welsh, 2014); these findings were similar with the current study. Effective communication in a family where parents listen to their children may help in understanding their physical, social, emotional, psychological and spiritual needs and also enable the parents to address those needs appropriately. Failure to pay attention to children's needs may lead to children feeling neglected and may develop conduct problems, as they try to cope with their issues.

As found out by Sanni etal, (2010): Ndaita etal, (2017) family factors like stability, cohesiveness, and adaptability play a crucial role in juvenile delinquency; and that children who are exposed to several episodes of violence within the family are likely to become offenders in their childhood through to their adulthood and hence an increase in Juvenile delinquency. This finding agreed with the current study which established that most families experienced conflict, violence and lacked a sense of togetherness.

On the expressiveness in the family, the study found out that the majority of the respondents did not at all talk openly in their homes, did not express their personal problems and did not start discussions easily. This findings were consistent with a study done by Odera (2013), in Kabete, Dagoretti and Getathuru rehabilitation centres in Kenya, which found out that $44 \%$ of the arrests were facilitated by family members and $22 \%$ of parents were alerted by police of their children's arrests; while $50 \%$ of the respondents reported that they had never been visited by any family members/guardians since arrival at the rehabilitation schools (2-3 years). This results demonstrated poor relationships among the respondents' families which further led to lack of communication, expressiveness, effective supervision and guidance. A study by Burfiend and Bartusch, 2010), argued that parents from poor families may not have time to supervise their children's behaviours, and they may instead use severe physical violence and verbal abuse. This was likely to lead to aggressive behaviour in children with the last resort being involvement with aggressive peers and violent behaviours. A study done by Atilola (2012), found out that Family background in Nigeria, for example, parental separation, family transitions like a change of babysitters, parental absenteeism in child development, plays a role in juvenile delinquency. He further stated that in the context of poor socio-economic circumstances, family instability is one of the major root cause of delinquency and other socially deviant behaviours in children. Family environment like poor or lack of supervision, physical violence and verbal abuse may determine the level, quality and content of communication and expressiveness among family members. Lack of expressiveness may lead to overwhelming negative feelings and emotions and due to stress negative coping mechanisms become inevitable to both children and their parents/guardians.

The study established that a majority of the families rarely helped or supported each other, they did not spend time doing things together and did not work hard together at their homes, and they were not proud of their families. These findings were similar with a study done in Arusha by Gudadi (2013), which found out that lack of parental supervision, family disruption and lack of information on the importance of family cohesion on raising up children has led to many children being delinquent. Lack of cohesion and expressiveness and the presence of conflicts in a family may affect children's development and behaviour negatively. These factors are often ignored in our society and even in the rehabilitation processes.

\subsection{Conclusion and recommendations}

The results found that the majority of the respondents were from families which were unstable compared to mere few who came from functional families. Lack of family cohesion, lack of expressiveness and high levels of conflict in the families of the respondents were among the family functions that were found to cause dsyfunctionality and contributing to delinquent behaviour among the children. The dysfuctionality caused poor communication and little or no support among family members leading to disruption and disunity in relationships in the families affecting how they catered for their needs emotionally, physically, socially, spiritually and financially. Family functions like communication, support, cohesion, expressiveness and conflict resolution play a vital role on how children develop in all aspects of their lives, and therefore family involvement in rehabilitation of children who are in conflict with the law is crucial in order to deal with the root cause of the delinquent behaviour.

This study created awareness of the aspects that are often ignored when dealing with children who are offenders and revealed why the rehabilitation process is sometimes ineffective, leading to recidivism. These aspects included the child's family and home environment.

Extensive involvement of counsellors and psychologist to carry out rehabilitation process instead of criminal justice personnel focusing on; Family therapy, cognitive behavioural therapy, community awareness forums on family dynamics is highly recommended.

The rehabilitation of the juvenile delinquent children should involve commitment of parents and guardians to counselling sessions, by the juvenile court. This would help in exploring of the family functions and dealing with the root cause of the delinquent behaviour instead of superficially addressing the problem by focusing on the child alone.

This study did not receive any funding from any organization or institution. 


\section{References}

1. Alnasir, F.A. \& Al-Falaij, A.A. (2016). Factors affecting juvenile delinquency in Bahrain. Journal of Practice, $\quad 4,229 . \quad$ Retrieved from www.researchgate.net/publication/293795700_Factors_Affecting_Juvenile_Delinquency_in_Bahrain

2. Atilola, O. (2012). Different points of a continuum? Cross sectional comparison of the current and pre-contact psychosocial problems among the different categories of adolescents in institutional care in Nigeria. BMC Public Health, 12(1). https://doi.org/10.1186/1471-2458-12-554

3. Boakye, K., Farrington, D., \& Loeber, R. (2008). Are Family Risk Factors Similar Across Cultures? A CrossNational Replicability of Family Risk Factors for Delinquency. Conference Papers -- American Society of Criminology, 1. Retrieved

from http://search.ebscohost.com/login.aspx?direct=true\&db=tsh\&AN=45000223\&site=ehost-live

4. Bt, W. N., Zulkifli, W., Azniza, N., Ishak, B., Bt, Z., \& Saad, M. (2017). The Reliability of Mcmaster Family Assesment Device (Fad) Instruments Among Delinquent Teenagers. IOSR Journal Of Humanities And Social Science (IOSR-JHSS, 22(7), 40-43. https://doi.org/10.9790/0837-2207054043

5. Burfeind, J. W., \& Bartusch, D. J. (2006). Juvenile delinquency: An integrated approach. (2006) Juvenile Delinquency: An Integrated Approach Xxi, 675 Pp Boston, MA, US: Jones and Bartlett Publishers; US. https://doi.org/S0142961202006105 [pii]

6. Ching Ting Fok, C., Allen, J., \& Henry, D. (2011). Relationship Dimension in Family Functioning. Journal of Abnormal Child Psychology, 21(1), 1-10. https://doi.org/10.1177/1073191111425856.

7. Epstein, N. B., Baldwin, L. M., \& Bishop, D. S. (1983). The McMaster Family Assessment Device * Previous First Next. Journal of Marital and Family Therapy, 9(2), 171-180. https://doi.org/10.1111/j.17520606.1983.tb01497.x

8. Fok, C. C. T., Allen, J., Henry, D., \& Team, P. A. (2014). The Brief Family Relationship Scale: A Brief Measure of the Relationship Dimension in Family Functioning. Assessment, 21(1), 67-72. https://doi.org/10.1177/1073191111425856

9. Gudadi, L. (2013). Dynamics of juvenile delinquency and crimes in Arusha city. Journal of Education and Humanities and Sciences 2, (1), 6-7

10. Hadfield, K., Amos, M., Ungar, M., Gosselin, J., \& Ganong, L. (2018). Do Changes to Family Structure Affect Child and Family Outcomes? A Systematic Review of the Instability Hypothesis. Journal of Family Theory \& Review, 10(1), 87-110. https://doi.org/10.1111/jftr.12243

11. Kabiru etal,. (2014). Adverse life events and delinquent behaviour among Kenyan adolescents: a crosssectional study on the protective role of parental monitoring, religiosity, and self-esteem. Journal of Child Adolescent Psychiatry and Mental Health 8 (24). Retrieved from https:// doi:10.1186/1753-2000-8-24

12. Maree, A. (2008). Criminogenic risk factors for youth offenders. In C. Bezuidenhout and S. Joubert (Eds). Child and youth misbehaviour in South Africa. A holistic approach. ( $2^{\text {nd }}$ edition). Pretoria: Van Schaik.

13. Mwanjala, C.S. (2015). Determinants of juvenile involvement in criminal behaviour in Taita-Taveta County, Kenya. Retrieved from www.semanticscholar.org $>$ paper $>$ Kenyatta-unive....

14. Ndaita, J. et al. (2017). Effect of counseling/modeling on behviour modification of juvenile delinquents in Eldoret and Kakamega rehabilitation centres. European Scientific Journal, 13 (32), 225

15. Nguku etal., (2017). Effect of counselling/modelling on behaviour modification of juvenile delinquents in Eldoret and Kakamega rehabilitation centres. European Scientific journal 13 (32). November 2017. https://doi: 10.19044/esj.2017.v13n32p225

16. Odera, T. (2013). Effectiveness of Rehabilitation Programmes on Juvenile Delinquesnts in Kenya. Journal Nordic Studies on Alcohol and Drugs, 2(3), 89-99.

17. Rwengo, Z. (2017). Factors influencing juvenile delinquency at Eldoret juvenile remand home, Kenya. Retrieved from: http://ir.mu.ac.ke.8080/xmlui/handle/123456789/832

18. Sanni etal., (2010). Family Types and Juvenile Delinquency Issues among Secondary School Students in Akwa Ibom State, Nigeria: Counseling Implications Raj 2010 J Soc Sci, 23(1): 21-28. Retrieved from https://pdfs.semanticscholar.org/78da/02b7197dc9b7bda5672b9ea71f460958f6da.pd

19. Saunders, M.N.K., Lewis, P\& Thornhill, A. (2016). Research Methods for Business Students (7th Edition) 7th Edition: England: Pearson Education Limited

20. Siegel, L. J., \& Welsh, B. C. (2014). Juvenile Delinquency: Theory, Practice, and Law. Teaching Sociology (Vol. 11). https://doi.org/10.2307/1317802

21. UN-HABITAT (2016). World cities report. UN-HABITAT. Retrieved from https://unhabitat.org>un-habitatlaunches-the-world-cities-report-2016

22. UNICEF Report. (2012). The state of the world's children 2012: Children in an urban world. United Nations Children's Fund Press.

23. Vincent, G.M., Guy, L.S \& Grisso, T. (2012). Risk assessment in juvenile justice: A guide book for implementation. New York: Models for Change. Retrieved from http://modelsforchange.net/publications/346. 
24. Wilson etal,. (2010). Quick, simple measures of family relationships for use in clinical practice and research. A systematic review. Retrieved from https://doi.10.1093/fampra/cmq080

25. Yamane, T. (1967). Statistics; An Introductory Analysis, $2^{\text {nd }}$ Ed. New York; Harper and Row 